\title{
Por qué es antidemocrática la secesión
}

\section{(Why secession is undemocratic)}

\author{
Mikel ARTETA
}

Recibido: 27 de noviembre de 2013

Aceptado: 16 de julio de 2014

\section{Resumen}

Trataré de demostrar que la secesión es intrínsecamente antidemocrática. Retomaremos los argumentos secesionistas: de aquellos que parten de una idea (errada) de autogobierno y de quienes lo hacen desde el liberalismo. Luego opondremos objeciones a ambos: defendiendo el valor de la igualdad; desmontando reivindicaciones instrumentales de homogeneidad interna; retomando las objeciones ya clásicas de Buchanan; y, finalmente, recomponiendo, con Habermas y Pogge, un concepto de autogobierno del cual derivaremos que no es legítimo trazar más fronteras y que la democracia demandaría eliminarlas, si fuera posible.

Palabras clave: Secesión, democracia, autogobierno, fronteras, Habermas, Dahl, Kymlicka.

\begin{abstract}
The aim of this paper is to prove that secession is inherently undemocratic. We will review the secessionist arguments: the one that starts from a wrong idea of selfgovernment and the one that starts from liberalism. Then, we will oppose objections to both: defending the value of equality; rejecting internal homogeneity claims; picking up Buchanan's classic objections; and finally, reformulating, with Habermas and Pogge, a concept of self-government in order to deduce that it is not legitimate to draw more boundaries because an ideal democracy would require to eliminate the current borders.
\end{abstract}

Keywords: Secession, democracy, self-government, borders, Habermas, Dahl, Kymlicka. 
Apresurémonos a excluir, de acuerdo con "criterios correctores", aquellos casos en que una minoría esté probadamente sometida a bélica anexión, a extorsión o expoliación de sus recursos, o violación constante de sus derechos fundamentales. ${ }^{1}$ El caso del Sáhara a manos de Marruecos cumpliría estos tres requisitos. Al margen de semejantes supuestos, en los que se centran las teorías del derecho terapéutico (Remedial Right Only Theory), y ateniéndonos meramente al principio de autogobierno, sostendremos que todo proyecto secesionista es, además de peligroso ${ }^{2}$, antidemocrático porque sólo se dirige a una parte del demos: aquellos con quienes pretende construir un nuevo proyecto político al margen de la soberanía popular, que en un sentido clásico reside en la fuente de una comunidad política previamente constituida. El secesionismo rompe la comunidad política que le antecede, sustituyendo el autogobierno de los más por el de los menos. Divide lo que en buena lógica democrática debería ampliarse: el conjunto de afectados que comprende que tiene algo en común (el padecimiento del riesgo, diría Ulrich Beck) y se entiende como un "nosotros" que debe acometer la tarea de domeñar los males, de hecho o potenciales, que le afectan. Así pues, aquí rebatiremos los fundamentos de las teorías de derecho primario (Primary Right Theory) que defienden un derecho general a la secesión.

Vayamos por partes. Hay quien advierte que el problema de la justificación de las fronteras en Estados con movimientos secesionistas importantes no tiene solución teórica. ${ }^{3}$ Aferrado a esta aporía, el secesionismo rechaza ajustar del mejor modo posible el autogobierno. ${ }^{4}$ Para dar respuesta recopilaremos primero los argumentos de los secesionistas de distintas posiciones teóricas (1). Nos centraremos después en argumentar por qué la secesión es antidemocrática, recordando que la igualdad es la base del proyecto político, y combatiendo los argumentos del comunitarismo liberal de Kymlicka A); y retomando luego los argumentos de Allen Buchanan contra la secesión B). Finalmente, reconfiguraremos con Habermas un concepto de democracia como autogobierno (aunando democracia y Estado de derecho) que nos permita afirmar que la democracia no admite crear más fronteras sino que, al contrario, demanda eliminar las que ya hay C) (2).

\footnotetext{
${ }^{1}$ Buchanan (2003), pp. 170-74.

2 Buchanan (2003), pp. 157-60.

3 Sánchez-Cuenca (2010), p. 54 y s. "La democracia puede 'verlo' o tratarlo todo excepto su propia constitución, que le está vedada. Ahí reside, si se quiere expresar así, su punto ciego".

4 Buchanan (2003), pp. 164 y s. Existen distintos encajes: derechos culturales de las minorías; derechos de cantones, estados o provincias dentro de federaciones; derecho de anulación y derecho de veto.
} 


\section{Los argumentos del secesionismo}

Nos interesaría no centrarnos aquí exclusivamente en los argumentos secesionistas que previamente se amparan en discursos etno-nacionalistas. Un simple acercamiento a la hermenéutica filosófica o a la razón comunicativa basta para rebatir a quienes, so pretexto de la inconmensurabilidad entre culturas (o incluso entre lenguas), niegan la posibilidad de alcanzar justos acuerdos políticos inter-pares (tomando ahora como partes a las comunidades nacionales que, como un mosaico, compondrían los sujetos morales del mundo). ${ }^{5}$ Tras astillar la razón, reniegan del carácter individual de los derechos culturales (como los lingüísticos); por eso exigirán que las naciones culturales muten en naciones políticas, o asuman al menos competencias especiales, e impongan "políticas del reconocimiento" que ayuden a perpetuar al grupo frente al efecto disgregador de las decisiones individuales. No obstante, aunque sea cierto que existen derechos cuyo ejercicio es colectivo, que requieren de una disposición distinta, no es menos cierto que las culturas sólo son importantes porque importan a las personas. ${ }^{6}$ Estos derechos no deberán fomentar ni perpetuar ninguna realidad social ${ }^{7}$, sino adaptarse a la que hay para garantizar a las personas (único sujeto moral posible) tanto el que puedan socializarse en una cultura como el que puedan dejar de hacerlo cuando lo deseen. ${ }^{8}$

Desgraciadamente abundan las coartadas filosóficas que esconden los intereses de unas élites nacionalistas que construyen la "nación" sin más intención que la de preservar o mejorar el estatus económico-político de la propia región. Cuando el chantaje no surte más frutos, se precipitarán las demandas secesionistas. ${ }^{9}$

Pero no por carecer de razones morales que lo sustenten ha dejado nunca el nacionalismo (siempre con la amenaza más o menos velada de la secesión) de estar representado políticamente, liderando programas que ven en la homogeneidad $u$ objetivación de una parte del demos (concentrada territorialmente) una oportunidad para reivindicar la secesión. Y los más avezados de entre ellos saben que, si pretenden convencer al observador más crítico y a la comunidad internacional, no irán

\footnotetext{
5 Gadamer (1998); Habermas (2000b), pp.127-231.

6 Appiah (2008), pp. 43-80.

${ }^{7}$ Arteta (2011), p. 37 y ss.

8 Benhabib (2006), p. 122.

9 "El nacionalismo engendra las naciones, no a la inversa": Gellner (1988), p. 136. "En el fondo del nacionalismo de la lengua hay problemas de poder, categoría, política e ideología y no de comunicación o siquiera de cultura”: Hobsbawm (2000) p. 120. En el capítulo 4 Hobsbawm expone el maridaje entre etno-nacionalismo e intereses político-económicos de las élites que construyen la nación. Respecto a Cataluña y País Vasco (pp. 116-117). En línea similar, Hetcher, para quien se trata de una alternativa arriesgada, afirma que sólo acaba decantándose por la secesión la región cuyas clases medias perciben incentivos privados (como la perspectiva de puestos de trabajo) y confían en su capacidad para hacer frente a la fuerza del estado anfitrión: Hetcher (1992).
} 
muy lejos centrándose en argumentos que, en plena modernidad, abocan a la construcción de un nuevo Estado sin pluralismo, sin tolerancia, antiliberal. 10 Por eso escrutarán vías alternativas que casen mejor con la conciencia liberal de nuestra época.

\subsection{Dos modelos de democracia para legitimar la secesión}

El nacionalismo, palanca del secesionismo, es una doctrina política que se distingue del resto de doctrinas en que, en lugar de tener un programa para el cuerpo político al que se dirigen, dirige sus inquietudes a una cuestión previa: su esencia consiste en preguntarse cuál es la comunidad política correcta, o sea, cuáles son las fronteras legítimas de la comunidad. Es una doctrina de la soberanía que defiende que el titular del poder último y originario reside en la nación. ${ }^{11}$ No parece difícil concluir que el nacionalismo es per se antidemocrático.

Pero tratemos de profundizar más en ello, distinguiendo conceptualmente dos ámbitos teóricos distintos de los que parte el secesionismo.

1. Hacen menos por alejarse del ideario etnonacionalista los seguidores de la teoría del Estado de Carl Schmitt: la democracia, o autogobierno, se equipara con la voluntad del pueblo encarnada en sus representantes y, por ende, en última instancia, en el poder ejecutivo con capacidad de decretar el estado de excepción; éste oculta el pluralismo al tenerse por el todo siendo sólo la parte $\mathrm{y}$, convencido de que su misión como soberano es permanecer en el ser (esa es la esencia de lo político), declara enemigo a todo aquel que se le enfrente, en el interior y en el exterior. ${ }^{12}$ Pero, puesto que esa doctrina obliga al Estado a enfrentarse al nacionalismo periférico en tanto enemigo interior, al nacionalismo no le quedará otra opción que realizarle a Schmitt una sustancial operación estética: el Estado no es el auténtico pueblo, o sea, la auténtica nación, sino que comprende varias naciones; el territorio que ellos deciden que es una nación es lo que ellos llaman "nación sin Estado", que aspira a ser Estado. Quedaría así abierta la vía a la legítima secesión de una nación, representada por el gobierno regional, para quien el gobierno del Estado matriz es el "enemigo".

Aferrado a una mal entendida libertad positiva, Sánchez-Cuenca trata de avalar el carácter democrático de la secesión a partir de una idea de autogobierno que, apoyándose en los "encompassing groups" de Margalit y Raz'13, identifica con "com-

10 "Las comunidades y grupos étnicos en las sociedades modernas forzosamente deben coexistir, prescindiendo de la retórica que sueña con que la nación vuelva a verse libre de mezclas. El asesinato en masa y la expulsión también en masa («repatriación») simplificaron drásticamente el mapa étnico de Europa y podrían probarse en algunas otras regiones": Hobsbawm (2000), p. 166.

11 Ruiz Soroa (2011), pp. 33 y s.

12 Schmitt (1991), p. 56. 
ponentes colectivistas y comunitaristas". ${ }^{14}$ Alegando que "el sujeto de la huelga son los trabajadores" (no los trabajadores que deciden hacer huelga: nótese ese "el...son"), procede a concluir, por analogía, que el sujeto de la autodeterminación es un colectivo nacional. ${ }^{15}$ En ambos casos toma al objeto de la acción por el sujeto. En esta línea, aunque reconoce que algunas personas (subraya que sólo una minoría) pueden adoptar una identidad más o menos cosmopolita, afirma, obviando la comparación y el juicio de valor, que "sentirse parte de una nación contribuye sin duda a forjar la identidad de las personas. En muchos casos puede llegar a ser un aspecto importante de sus vidas". Aquí emite un juicio de valor por la puerta de atrás, acomodado en la falacia naturalista, que vendría a apreciar esas identidades basadas en (anuladas por) la identidad del grupo. ${ }^{16}$ Su definición sesgada de autogobierno, asentada en el principio de las nacionalidades, su desinterés por lo estatal, que es el elemento institucional con capacidad de garantizar el autogobierno, y su idealización romántica de nación como ente creado a voluntad, le permite reprochar a los que son contrarios a la secesión lo siguiente: "es como si la lógica de la conservación de los estados tuviera mayor peso que consideraciones democráticas acerca del ejercicio del autogobierno por parte de grupos nacionales territorialmente concentrados". 17

2. Otros secesionistas prefieren partir de una democracia contractualista 18 que comprende una lucha política a través de elecciones y la garantía o protección de determinadas libertades básicas. Se trata de una idea de democracia liberal bastante extendida, de la que Robert Dahl o Schumpeter podrían ser buenos representantes.

Todos ellos temen lo que Tocqueville denominó "tiranía de la mayoría". Por eso, sin renunciar al voto y a la participación política, prefieren destacar el estado de derecho, subrayando la existencia de mecanismos contramayoritarios, como aquellos derechos que garantizan la libertad plena de cada ciudadano. Pero, incluso quienes más se alejan de la democracia de mercado suelen conformarse con un entramado institucional que, al margen de la democracia, garantice la poliarquía ${ }^{19}$, la no dominación ${ }^{20}$ o, en general, las decisiones correctas.

\footnotetext{
13 Margalit \& Raz (1990).

14 Sánchez-Cuenca (2010), p. 72.

15 Sánchez-Cuenca (2010), p. 77.

16 Miller (1995), cap. 3.

17 Sánchez-Cuenca (2010), p. 87.

18 Buchanan (2003), p. 175. Para éstos, "el único modo de garantizar que los ciudadanos den efectivamente su consentimiento es permitirles 'abandonar' la esfera de control del Estado si así lo eligen". Es decir, "aquellos que no consienten la autoridad del Estado deberían poder constituir su Estado propio mediante un consentimiento otorgado a otros individuos con sus mismas ideas".

19 Dahl (1990a).

20 Pettit (1999).
} 
Aunque es difícil, desde el apego a la libertad negativa, encontrar razones democráticas a favor de la secesión, también es difícil encontrarlas en contra. Por eso sirven a los primeros de escuderos: tras pasarle la carga de la prueba al Estado, muchos abogan por esgrimir estos argumentos, conscientes de la dificultad de encontrar razones analíticas en contra de la secesión así planteada.

Será difícil que bajo los argumentos de los que así defienden la secesión no subyazca un ideal comunitarista. Kymlicka, apelando a una premisa instrumental, afirma que si una comunidad quiere funcionar correctamente necesita preservar una cierta homogeneidad: si bien los objetivos de la democracia y los derechos humanos son "cosmopolitas" (brindis liberal), el marco adecuado de realización de la democracia es el nacional porque la deliberación política requiere del "ámbito vernáculo" de los hablantes de una lengua para garantizar la comprensión y confianza mutuas. ${ }^{21}$ Alude para ello a un experimento tras el velo de la ignorancia ${ }^{22}$, asegurando que la gente preferiría compartir lazos culturales y lingüísticos con los miembros de su comunidad a cambio de perder movilidad. Pero no se trata de una cuestión meramente lingüística: "es posible que se requiera un cierto sentido de vida común o de identidad compartida para sostener una democracia deliberativa y participativa". ${ }^{23}$ Por eso mantiene la necesidad de crear nación (sin creer en la arcadia primigenia de raza inmaculada, sino apelando a la historia del nacionalismo liberal24), mediante unas fronteras (si no estatales, sí regionales y con autogobierno25).

Exageran y ocultan alternativas cuando afirman que la solidaridad que requiere el Estado de bienestar sólo puede esperarse de una comunidad unida afectivamente; de esta premisa pasan a concluir arbitrariamente que el Estado nacional sigue siendo el marco más adecuado para el correcto desarrollo de la ciudadanía y la democracia. La diversidad requeriría, según David Miller, que la vida política se asiente en comunidades distintas. Por eso el cosmopolitismo estaría abocado al fracaso.

Si las identidades nacionales empiezan a disolverse, la gente corriente tendrá menos razones para ser ciudadanos activos, y las élites políticas tendrán manos libres para desmantelar aquellas instituciones que actualmente contrapesan, en cierta medida, el mercado global. ${ }^{26}$

\footnotetext{
la unión federal, En: Dahl (1999b), pp. 176 y s.

22 Kymlicka (2006), pp. 70 y s.

23 Kymlicka (2003), p. 382; (Kymlicka (2006), pp. 66-68.

24 Kymlicka (2006), p. 52 y ss.

25 Kymlicka (2006), p. .45 y pp. 70 y ss.

26 Miller (1997), p. 228.
}

21 El propio Dahl sostiene que la secesión sólo es posible cuando las subculturas están separadas por líneas territoriales; y aunque divididos en unidades autónomas, los ciudadanos deben poseer una identidad nacional y objetivos y valores comunes que sean lo suficientemente fuertes como para sostener 
No obstante, la uniformidad institucional, lograda con la imposición coactiva de un ordenamiento común sin arraigo efectivo, arrojaría un resultado empobrecedor.

\subsection{Itinerario del secesionismo}

1. Desde cualquiera de los dos asideros teóricos alegarán, en un primer y acertado paso, que las fronteras no están justificadas, pues obedecen a contingencias históricas. De entre ellos, los que se agarran a la segunda corriente, afirmarán también que la solución o justificación de esas fronteras no puede pasar por objetivar el demos que cae dentro de las fronteras, pues eso legitimaría unas políticas de inmersión étnicas y homogeneizadoras incompatibles con su núcleo liberal. (Por supuesto, se habrán producido ya, con su connivencia, las transformaciones políticas deseadas por los adalides de un discurso etno-nacionalista que no ha dejado de tener vigencia y legitimación social). ${ }^{27}$ Llegados a este punto, la corriente más liberal del secesionismo podrá afirmar que éste no es ni democrático ni antidemocrático: simplemente se trata de algo discrecional porque la determinación de las fronteras o configuración del demos es una cuestión previa a la institucionalización de la democracia.

2. El separatismo liberal formula entonces una pregunta trampa: ¿cómo solucionar un conflicto de fronteras entre el Estado y los secesionistas si no queremos acabar dando ventaja injustificada (ellos dirán directamente injusta) a una de las dos partes en conflicto? Descartan de entrada que podamos querer priorizar a una de las partes y nos obligan a tratar la cuestión siguiendo la analogía con el matrimonio. Sin justificación el Estado se convierte en un contrato privado entre dos sujetos de derechos cuyas autonomías (orgánicas) hay que salvaguardar.

Han dado ya el siguiente paso. Puesto que las fronteras no están justificadas, puesto que eso hace de los cuerpos soberanos o naciones políticas actuales simples abstracciones útiles para gobernarnos, y puesto que el gobierno democrático (reducido al electoralismo y mayoritarismo) puede aflorar en cualquier comunidad que se lo proponga (o sea, podrá coexistir en las dos partes separadas tras la escisión del cuerpo primigenio), habremos de hallar una solución razonable para ambas partes que no pase por perpetuar el statu quo. ¿Cuál? Una discusión/negociación de buena fe entre las dos partes. Y dada esta equidistante y sólo aparentemente razonable premisa, si alguien se niega a negociar, el otro gana directamente legitimidad para actuar unilateralmente. Eso es lo que parecen creer y, para sostenerlo, no habrá secesionista que no se acoja a la sentencia que el Tribunal Supremo de Canadá dictó en 1998. Ambigua sentencia que, a pesar de su jubiloso ruido, no refrenda a los antifederalistas tanto como desearían.

27 Ovejero (2006) 
Conviene aclarar algunas cosas: la primera, que en Canadá la secesión no es un derecho sino una posibilidad contemplada legalmente; la segunda, que en ningún caso es una posibilidad legal unilateral ("sea cual sea la definición exacta de pueblo(s) que se aplique a este contexto, el derecho a la autodeterminación no puede ser, en las circunstancias actuales, el fundamento de un derecho a la secesión unilateral") y que, por tanto, un referendum afirmativo no tiene efectos jurídicos inmediatos; y esto nos lleva, como tercer apunte, a recordar que lo que concluye el Tribunal Supremo de Canadá es que, aunque la comunidad internacional no reconoce la secesión (salvo criterios correctores que no concurren, obviamente), es "probable" que a pesar de todo al final se obtuviera dicho reconocimiento. Pues bien, el secesionismo suele pasar estas advertencias por alto y se acoge a las siguientes palabras: "un voto mayoritario claro en Quebec a una pregunta clara a favor de la secesión conferiría una legitimidad democrática a la iniciativa de la secesión que el resto de participantes en la Confederación debería reconocer" (cursiva mía).

El caso es que, en 1998, con una pregunta muy confusa ("¿acepta usted que Quebec sea soberano después de haber ofrecido formalmente a Canadá una nueva asociación económica y política en el marco del proyecto de ley sobre el futuro de Quebec y del acuerdo firmado el pasado 12 de junio?"), que no hubiera cerrado la secesión en caso de que Canadá hubiera aceptado (en el lapso de tiempo que va entre el hipotético resultado favorable a la secesión y la secesión efectiva) la "asociación económica y política brindada", los soberanistas consiguieron el 49,4\% de los votos en un segundo referéndum. Por cierto que, en el 2000, tras ver cómo el nacionalismo se prestaba a traicionar el espíritu y la letra del Tribunal Supremo, el Parlamento de Canadá decidió aprobar la ley de Claridad (Clarity Act) con lo que la "pregunta clara" debía ser: "independencia sí o no" y la mayoría clara, a determinar, pero en todo caso superior al 50\% más uno. Apuntes razonables, rechazados por el nacionalismo.

3. De lo anterior hay quien deduce que no hay razones morales contra la secesión 28 y que acepta tomar a la parte secesionista como sujeto político/soberano para decidir sobre la secesión. Analíticamente, conceden que la democracia liberal podría implantarse en un Estado o en sus diferentes escisiones, sin mayores consideraciones morales. O aun, negativamente: que las nuevas fronteras tienen tantas consecuencias morales como las tenían aquellas antiguas que el Estado da por buenas. Y, por tanto, que en cualquier caso, frenar la secesión de una parte del Estado cuyas fronteras no son justificables equivale a dar injustamente ventaja al "nosotros" que representa el Estado sobre el "nosotros" separatista. En definitiva, haciéndose eco de las palabras de Robert Dahl, afirman que: "para resolver esta problemática, la teoría democrática no nos lleva demasiado lejos. Las ideas democráticas no

28 De nuevo, para refutar esa tesis: Ruiz Soroa (2011). 
nos dan una respuesta definitiva; presuponen que ésta ya ha sido dada, de algún modo, por la historia y la política, o que lo será. (...) La dificultad no radica en que sea imposible formular juicios razonables sobre qué es mejor y qué es peor, sino en que tales juicios serán probablemente poco concluyentes y muy controvertibles".29

4. Finalmente reciclarán el argumento que el liberalismo esgrime contra el comunitarismo cuando, aferrándose a la composición social de las identidades individuales, pretende salvarnos de la angustia existencial imponiéndonos una identidad colectiva. Si el liberalismo descubría que el individuo-sin-cultura es la premisa falaz del comunitarismo para ahormar nuestras elecciones vitales a la forma preconcebida de metafísicos sujetos colectivos (pueblos), análogamente, el nuevo independentismo pretende que los no independentistas se contenten, advirtiéndoles de algo en lo que no habrían reparado: la secesión no tiene relevancia moral porque los excluidos por el proyecto separatista seguirán siendo ciudadanos de otro proyecto político. No se harían no-ciudadanos, por lo que no habría diferencia entre el antiguo demos y los dos nuevos; salvo que los segundos serían mejores por resultar de una solución razonable mientras que el primero era históricamente contingente y no justificado. Hacen así buena la siguiente afirmación: "presuponiendo que para un cierto conjunto de personas resulta valioso el proceso democrático, sus virtudes pueden alcanzarse mejor a veces modificando los límites de la unidad política".30

Resulta muy poco probable encontrar casos de secesión por mutuo acuerdo que den lugar a la existencia de dos nuevos estados. Y los que haya (Checoslovaquia se acerca, pero no se hizo con respaldo popular) son marginados por teóricos como Buchanan porque donde no hay conflicto no hay nada que resolver. Pues bien, incluso dicha separación es conceptualmente antidemocrática.

\section{La secesión es antidemocrática}

¿Qué pasa si, contra la opinión de Dahl, sí existen buenas razones democráticas para dar ventaja a una de las dos partes en conflicto? Nos referimos a la que ya nos viene dada y, por ende, la más grande: el Estado, en este caso. Quizás conviene aclarar que con nuestra tesis se está distinguiendo entre un derecho democrático/moral a la secesión (que es el que aquí negamos, salvo tasadas excepciones) y un derecho legal a la secesión. Pero, con todo, incluso este derecho legal genera dudas: habitualmente se cuelan por ahí pulsos chantajistas y populismos que, buscando la confrontación, tratan de crear un clima de crispación tan inasumible que obligue al gobierno a tomar cartas. 31

\footnotetext{
29 Dahl (1999a), p. 253.

30 Dahl (1999a), p. 178.

31 Uno se pregunta cómo debe actuar el Estado ante quienes, sin poder aportar ninguna razón legítima, abogan por aseverar que "sólo una patente inestabilidad interna que impida a la comunidad inter-
} 


\subsection{Dos objeciones a las tesis secesionistas}

\subsubsection{La igualdad como base del proyecto político}

Reconocer que las fronteras son contingentes y proponer luego una forma política en el interior implica ya, para el secesionismo, dar por buenas/justificar las fronteras. Advierten que se estaría así privilegiando a la parte mayoritaria de la población. 32 Esto les parece injusto porque, aunque pudieran aceptar que trazar nuevas fronteras tiene implicaciones morales, sólo lo harían con la condición de que aceptemos que las fronteras actuales también las tienen, que no son moralmente neutras. Esta crítica, más o menos sutil, no descansa hasta predecidir quiénes son los míos de cara a confeccionar al cuerpo que decida sobre la secesión: se otorgan a sí mismos una identidad jurídica y política vedada que presumiblemente ya les brindaría la mayoría en el hipotético referendum. Y eso debe ser así, dicen, porque si no, nunca podrían ser mayoría...

Obviando las múltiples trampas lógicas, en primer lugar cabrá reprocharles que jamás conseguirán tener mayoría con un programa político que persevera ontológicamente en el "ser". Evidentemente siempre serán una minoría dentro de un Estado. Tampoco los pelirrojos, por cierto, podrán ser mayoría (salvo que impongan el tinte obligatorio). Pues bien, justamente esto (la imposición) es lo que tratan de hacer a la desesperada la mayoría de movimientos de secesión. Se aferren a la pureza argumental y analítica a la que se aferren, su silencio ante los atropellos presentes les delata cuando se aprovechan de políticas antiliberales de homogeneización y renacionalización del demos; son ellas las que van permitiendo generar nuevas mayorías que las más de las veces no tenían de partida. Se entiende así que aquello de lo que teóricamente prescinden por iliberal en realidad nunca ha dejado de salir del programa político de la secesión; simplemente se oculta a conveniencia.

Por eso, lo que cabe oponerles luego es que las consecuencias morales de la secesión son los reiterados chantajes de una parte (generalmente los ricos) al todo. A eso dará pie la simple posibilidad de secesión. No es difícil advertir cómo ese chantaje permite amasar cuantiosos privilegios a las regiones que juegan esa carta. Y, finalmente, aún cabe recordar que hay otra consecuencia (teórica y moral) relacionada con el retroceso democrático, tal y como ha quedado expuesto.

En lugar de centrarse en el "ser", la política deberá reducirse a proyectos que tengan por base la igualdad, que puedan buscar la adhesión de todos porque buscan sinceramente atender al interés general (no al interés de los más y desde luego no al interés de los míos o de unos pocos). Decir por ejemplo que, aceptadas nuestras

nacional mirar para otro lado, hace posible la secesión" (http://www.cerclegerrymandering.cat/allenbuchana-independencia/).

32 Dahl (1999a), pp. 177 y s. 
determinaciones, la justicia exige de cada cual según sus capacidades y darle a cada cual según sus necesidades; o decir que para hacer justicia en una comunidad política, pese a la arbitrariedad de las fronteras, se requiere que la soberanía nacional se convierta hoy en soberanía popular, en ningún caso significa justificar una arbitrariedad sino hacerse cargo de ella.

Hacerse cargo también, por cierto, de las consecuencias actuales de las decisiones y planificaciones que la comunidad política proyectó en el pasado. Por ejemplo, contra lo que hoy pretende imponernos la Generalitat (recurriendo a historiadores más leales a la causa que a la técnica histórica), es necesario afirmar que la tesis según la cual habría habido una opresión de los Borbones contra Cataluña (que aun así habría llegado a ser una región próspera) incurre en una doble falacia. En primer lugar, porque la Guerra de Sucesión fue a la vez una guerra internacional, dinástica y civil: los fueros se quitaron por deslealtad, no por antiforalismo borbónico; pero en ningún caso caben lecturas simplistas, pues borbones y austracistas los hubo tanto en Cataluña como en Madrid. En segundo lugar, la falacia oculta que desde el siglo XVIII se fomentó la industria del Principado, suprimiendo aduanas interiores para favorecer el comercio interior, reduciendo días festivos o bajando ahí presiones fiscales (con un impuesto novedoso, el catastro) con respecto al resto del Estado. ${ }^{33}$ Que la industria catalana sea más próspera se debe también a la planificación estatal; otras regiones debían centrarse en la agricultura, infinitamente menos productiva, y hacer uso de las transferencias de renta organizadas por el Estado para comprar/dar salida a los productos manufacturados en las regiones más prósperas (esto, por cierto, hoy se reproduce en la UE, como muestra la enorme partida presupuestaria destinada a la Política Agraria Común -que anima a determinadas regiones, tildadas luego de vagas, a persistir en la agricultura por el bien de conjunto: como advierte Stiglitz ${ }^{34}$, se trata de mantener al tercer mundo en el subdesarro1lo, incapacitándolos para exportar productos agrícolas que aquí subvencionamos, impidiendo el paso a su industrialización e inhabilitándoles para incrementar su parte en el mercado mundial-). Si esto es así, cabe preguntarse si la secesión no comete injusticia contra los herederos, agraviados por dicha planificación. Al no buscar ni hacer justicia hoy ni deshacer las injusticias heredadas, el secesionismo resulta antipolítico.

Más nos valdría ampliar las miras. Una identidad no humillada se forja, como muestra Axel Honneth ${ }^{35}$, con amor/cuidado, reconocimiento jurídico como un igual político en abstracto (ciudadano con derechos y obligaciones) y reconocimiento de su proyecto de vida buena, de su individualidad. Deudor del triple reconocimiento, será necesario poner donde corresponda a la figura del hombre reciprocante que

\footnotetext{
33 Pérez Sarrión (2012), cap. V y VII

34 Stiglitz (2006), pp. 122 y ss.

35 Honneth (1997)
} 
somos y que clama justicia. Se entienda ésta de forma procedimental o de forma material, la justicia es una reivindicación que interpela al otro y exige, a veces una reciprocidad en el trato y, a veces, una reparación por las injusticias sufridas o heredadas. Por eso, un proyecto cuyos principios no son universalistas ni buscan serlo no puede ser equiparado a un proyecto integrador. Lo que nos permite atender sin dificultades a Aristóteles, a Kant, a Rousseau, a Marx o a Habermas, por poner ejemplos, es que todos ellos se dirigen al conjunto de ciudadanos como iguales. Algunos de ellos defenderán una democracia formal con honestidad y otros plantearán, también con honestidad, críticas materiales que señalen la vacuidad de dicho procedimiento... Pero con honestidad uno no defiende un proyecto excluyente.

El proyecto democrático será legítimamente revisable desde dentro. Ésa es la apoyatura de la objeción de conciencia ${ }^{36}$, que sólo es legítima cuando, apelando a valores universalistas (principios constitucionales), trata de buscar sinceramente el apoyo de la mayoría. Por esta vía, desde el propio sistema se irá reconfigurando el demos, plasmando esa tendencia universalista del individuo liberal y dibujando un "nosotros" cada vez más completo, igualitario y universalista.

\subsubsection{Los límites del pragmatismo comunitarista}

La apelación pragmática a la homogeneidad interna del demos no explica por qué debe corresponderse el nivel étnico con el político (pero así justificarán la construcción nacional ${ }^{37}$ ). La federalización de los Estados nacionales a partir de entes caracterizados por la lengua y la adhesión del imaginario social a lazos culturales e históricos comunes ${ }^{38}$ no explica cómo garantizar la diversidad y los derechos de las nuevas minorías. ${ }^{39}$ Menos aun trata de integrar la inmigración, a la cual opone una "capacidad de absorción" no relacionada con el mercado de trabajo sino con la identidad nacional del Estado receptor: aunque asegura que no invoca al ámbito privado, religioso o ideológico, es obvio que no remite a la cultura política democrática en tanto patriotismo constitucional. 40

Nunca el Estado nacional ni las regiones que lo componen han sido homogéneos por dentro. ${ }^{41}$ El pluralismo cultural, al dibujar la diversidad como un mosaico, comete un absurdo antropológico ${ }^{42}$ que, tras separar a las comunidades en unidades homogéneas, trata de forzarnos a respetar la diversidad.

\footnotetext{
36 Habermas (1988), pp. 51-71.

37 Kymlicka (2006), pp. 60 y 70.

38 Kymlicka (2006), p. 52.

39 Kymlicka, 2006), pp. 63, 67 y 73 Para una respuesta a Kymlicka: Benhabib (2006), pp. 110-126.

40 Kymlicka (2006), pp. 62 y 64 Sobre el concepto de patriotismo constitucional en oposición a estas ideas: en Habermas (1999b), pp. 189-227. Y ver también: Habermas (1999a), pp. 123-126.

41 Brunkhorst (2008), 494 y ss.

42 Benhabib (2006), p. 123 Cita aquí a Gupta, Akhil y Ferguson, James (1992), "Beyond 'culture': space, identity, and the politics of difference', en Cultural Anthropology, vol. 7, $\mathrm{N}^{\circ} 1$.
} 
Consciente del carácter construido del Estado nacional ${ }^{43}$, Kymlicka se centra en la unidad lingüística, relegando a un segundo plano alguna información fundamental: en primer lugar, que la democracia no es vernácula en la India actual o en Suiza, por ejemplo, y sin embargo funciona; y en segundo lugar, que la política actual es y debe ser "metavernácula". ${ }^{44}$ Además, por supuesto, se omite que los interesados en crear nación son las regiones más ricas. Por ello es bueno subrayar con Benhabib que "la cultura es política" 45 ; no es algo previo a lo que la política se deba someter.

Parece algo cínico que Kymlicka trate de poner un límite contra los estatistas que pretenden excluir al otro de los recursos: contra ellos apela demasiado vagamente a la necesidad de ocuparse de la redistribución antes de acometer cualquier política de exclusión. ${ }^{46}$ Pero, como veremos más adelante, ocuparse de la redistribución (que es el elemento democrático del par) implica oponerse a la exclusión: más que orden temporal hay una contradicción lógica.

En definitiva, Kymlicka no contempla los derechos de las nuevas minorías; no queda claro por qué el Estado es el ámbito de la nación 47 ; se centra en ambiguos lazos culturales más que en la cultura política democrática, etc. Y es que la premisa instrumental no puede ser definitoria. No es un argumento a favor de la secesión ni contra el potencial cosmopolita que nosotros sostenemos que es intrínseco a la democracia; como mucho muestra la necesidad de plantear la relación entre cosmopolitismo y Estados en términos, no de exclusión, sino de complementariedad. 48

\subsection{Objeciones de Buchanan a la secesión}

La primera objeción que plantea Buchanan ${ }^{49}$ a la secesión es que la amenaza de irse es un chantaje que pervierte el procedimiento, pues "una minoría podría, en la práctica, ejercer un veto siempre que los procedimientos democráticos pudiesen producir un resultado no deseado por ella". 50 Traducido al lenguaje de la democracia deliberativa: el mero hecho de poderse levantar de la mesa (la mera posibilidad legal de independizarse) acaba de raíz con el "valor epistémico" de la democracia, es decir, con la presunción de corrección de las decisiones. ${ }^{51}$

\footnotetext{
43 Kymlicka (2006), p. 65.

44 Kymlicka (2003), p. 263.

45 Benhabib (2006), p. 201.

46 Kymlicka (2006), pp. 76 y ss. Sobre ese defecto es sobre el que pretende hacer hincapié Seyla Benhabib, en: Benhabib, Waldron, Honig, Kymlicka, \& Post (2006), p. 175.

47 Benhabib et al. (2006), p. 172.

48 Benhabib et al. (2006), pp. 176 y s.

49 Buchanan (2013).

50 Buchanan (2013), prólogo a edición española.

51 Habermas (2009), pp. 136-183.
} 
La segunda objeción tiene que ver con el falibilismo propio del procedimiento democrático cuyo valor epistémico sólo puede entenderse in the long run. Esta idea, que viene a reciclar la defensa de la libertad que ya hizo en su día Stuart Mill, implica que, del mismo modo que la teoría de la democracia prevé siempre unos derechos para garantizar que las minorías de hoy podrán ser las mayorías del mañana, la independencia es un problema porque impediría a los ciudadanos (los de ambos fragmentos disgregados) deshacer el camino andado.

Se diría que ambos argumentos confirman que la independencia es antidemocrática. No obstante, quedamos desconcertados cuando Buchanan concede al secesionismo que el replanteamiento de las fronteras estatales "también tiene sentido desde el punto de vista de los valores democráticos ya que, al menos en algunos casos, la democracia funciona mejor a menor escala". 52

\subsection{La democracia como "autogobierno" y su tendencia cosmopolita: menos} fronteras sí; más fronteras no

\subsubsection{Hacia un concepto válido de autogobierno}

Aclaremos de entrada que según cómo definamos la democracia juzgaremos la secesión como algo previo a la democracia y por tanto no evaluable en términos democráticos o, como defendemos aquí, como algo simplemente antidemocrático. Definamos primero la democracia y deduzcamos luego su potencial normativo.

Resulta que conformarse con calibrar como democrático a un sistema político por garantizar la lucha electoral, el mayoritarismo y unos derechos fundamentales básicos es conformarse con un modelo descafeinado; uno que ha perdido, de hecho, la esencia del propio concepto de democracia, que era el autogobierno del pueblo; uno que se separa de quienes recogen el legado de esa esencia, el republicanismo, y se contenta con los límites liberales (contramayoritarios) que la sabia teoría ha ido imponiendo a ese autogobierno para evitar la "tiranía de la mayoría". Es la definición realista, sin grasa, que la ciencia social ha potenciado para poder cuantificar y comparar entre distintos regímenes democráticos. Una que menosprecia el autogobierno y a cambio tampoco nos revela cómo debe ser la democracia ni cuál es su potencial normativo. Con ese punto de partida todo Estado puede ser democrático; y tan democrático sería el Estado primero como los dos fragmentos desgajados. Este es el efecto de centrarse en la parte liberal de las democracias liberales, es decir, en esa que trata de poner límites a las peores derivas del autogobierno. Se produce ahí un sesgo que debilita el factor del autogobierno a favor del secesionismo.

52 Buchanan (2013), prólogo a edición española. 
Por otra parte, al calificar a la nación simultánea y cumulativamente como un hecho y como un valor, como el origen exclusivo de la legitimidad o la soberanía, el comunitarismo acabará reduciendo la democracia a un núcleo de normas o principios necesarios y no revisables, deducidos obligatoriamente de ese origen (tesis de la correspondencia necesaria). A esto se suma la infrainclusividad por definición de una nación entendida en términos, cuando menos, de sentimiento y adhesión (cuando más, por rasgos diacríticos como la lengua o la raza). Esto es lo que crea una frontera interior que ilumina a unos y oculta a otros a los que tratará de "normalizar" mediante políticas de perfeccionismo, imponiendo una vida buena en contra de la esencia liberal de la dignidad y la autonomía de las personas. Y, en cuarto lugar, podrá ya pasar a buscar la estatalidad. ${ }^{53}$ Tras desvelarnos agudamente este itinerario nacionalista, Ruiz Soroa concluye que, "así entendida, la reivindicación nacionalista se vuelve radicalmente incompatible con la democracia en tanto en cuanto implica someter algunos valores democráticos esenciales (los de igual dignidad y autonomía de los ciudadanos) a otros valores particulares deducidos de la verdad propia nacionalista". 54 De ahí deduce que, respecto a los Estados nacionales ya existentes, la denunciada incompatibilidad se manifiesta en la exigencia democrática de desnacionalizar el Estado. Y, en cuanto al nacionalismo periférico o sin Estado, "la exigencia también democrática de renunciar a la secesión", salvo en los supuestos correctores ya mencionados. 55

Sin embargo, contra las dos caracterizaciones de la democracia que pretenden ser compatibles con la secesión, aquí se propone otra más acorde con la sustancial idea de autogobierno que, al mismo tiempo, retome el mejor legado liberal. Se dará por bueno que la democracia liberal (o constitucional) es lo que da a ese autogobierno un criterio más allá de la mera legitimación que aportan, respectivamente, la deliberación pública, el procedimiento público-político (cuya formalidad genética vela la igualdad de oportunidades de la que dice partir) y la teóricamente posterior (y última) regla de la mayoría. ${ }^{56}$ El liberalismo aporta garantías frente al falibilismo (en tanto las minorías siempre deben poder convertirse en mayorías -cosa que niega el secesionismo al buscar la escisión definitiva de una parte del demos-) y la defensa de cierto universalismo moral (en cuanto todo ser humano tendría protegida su dignidad gracias a la operatividad de unos derechos fundamentales -que sólo

\footnotetext{
53 Ruiz Soroa (2011), p. 36-42.

54 Ruiz Soroa (2011), p. 42.

55 Ruiz Soroa (2011), p. 42.

56 Como afirma John Dewey (y retoma Habermas), "la regla de la mayoría, justo como regla de la mayoría, es tan tonta como sus críticos dicen que es. Pero nunca es simplemente la regla de la mayoría... Los medios por los que una mayoría llega a ser una mayoría es aquí lo importante: debates previos, modificaciones de los propios puntos de vista para hacer frente a las opiniones mayoritarias... La necesidad esencial, en otras palabras, es la mejora de los métodos y condiciones del debate, de la discusión y la persuasión", en: Habermas (2005), p. 380 y s.
} 
aparentemente, o formalmente, pueden ser garantizados en cualquier comunidad política-).

Pero, como advierte una razón postmetafísica que necesita bailar con el positivismo, todo este armazón, monológicamente pensado por la cabeza del teórico de la democracia ${ }^{57}$, no se "aporta" a nuestras constituciones de forma exógena, sino que sólo el autogobierno, nuestra decisión procedimentalmente legitimada y fáctica, puede positivar todos esos resortes y garantías para las minorías. Siguiendo esta vía que nos impone la "forma" jurídica, quizás debamos prestar por un momento algo menos de atención al estado de derecho, o a la poliarquía, e incidir momentáneamente más en el elemento propiamente democrático, que es el "autogobierno". Veremos que la cosa cambia un poco.

La democracia ateniense era un modelo de gobierno que le daba poder al pueblo. No serían ni los aristoi (los mejores) ni los oligoi (los más ricos) los que debían gobernar. Ni el filósofo rey ni la mejor oligarquía sino el pueblo, o sea, el conjunto de los ciudadanos, aquellos que simplemente tenían libertad. No obstante, este concepto clásico que nos lleva al autogobierno del pueblo no aclara cuál es el pueblo. ${ }^{58}$ Habermas, por ejemplo, expone del siguiente modo el principio democrático:

Sólo pueden pretender validez legítima las normas jurídicas que en un proceso discursivo de producción de normas jurídicas, articulado a su vez jurídicamente, puedan encontrar el asentimiento de todos los miembros de la comunidad jurídica. 59

Respecto a los afectados, matizará que, a diferencia del principio moral, el principio democrático apela al conjunto de los miembros de una comunidad política temporal y espacialmente determinada y no a la humanidad en general. De ahí que él admita que "la pregunta por la legítima composición de la totalidad de base de los ciudadanos permanece abierta mientras la autodeterminación democrática únicamente concierna al tipo de organización de la convivencia de los miembros asociados de la comunidad jurídica". 60

\subsubsection{Más fronteras, no: trocar la soberanía nacional en soberanía popular}

Dice Habermas que "resulta insuficiente la respuesta circular de que los ciudadanos mismos se constituyen como pueblo y con ello delimitan su espacio respec-

\footnotetext{
57 La Carta de la Tolerancia, de John Locke, podría abrir la etapa del liberalismo entendido como líneas rojas del procedimiento democrático.

58 Rancière (1996), p. 45. La grandeza de esta indeterminación reside, para Rancière, en que otorga una fuerza normativa inagotable a la política (que él equipara con la democracia) cuya propiedad es tratar siempre de conseguir que pasen a contar los incontados, los que siendo pueblo no son tenidos en cuenta.

59 Habermas (2005), p. 175

60 Habermas (1999), “Inclusión: ¿incorporación o integración?”, p. 119.
} 
to al entorno tanto social como territorialmente". 61 No obstante, como tampoco querrá cerrar en falso el problema (como hace el comunitarismo, ejerciendo una asimilación injustificada sobre los ciudadanos), tras dar por arbitrarias las fronteras se verá obligado a proponer una vía para paliar esa mácula genética.

Ciertamente, para que la arbitrariedad del cierre del demos no afectase al autogobierno, durante el siglo XIX se promovió la nacionalización del pueblo. Pero fue el proceso de desnacionalización, con el que acogimos democráticamente la diferencia, lo que abonó el campo para el desafío secesionista de nacionalismos periféricos.

Como un cierre justo (y liberal) de las fronteras no soporta objetivar al demos en torno a unos rasgos diacríticos escogidos por la élite de turno, la única solución que dará la teoría del discurso es ejercer legítimamente esa soberanía nacional que nos viene dada desde que el demos hizo suya la soberanía del monarca absoluto, haciendo efectiva la "soberanía popular". Esto implica aunar la idea de constitución (sobre todo su parte dogmática o "sistema de los derechos") con la de democracia, sin la cual no habría autoorganización política. 62 Para ello un estado de derecho instituye un procedimiento cuya fuerza epistémica radicará en su capacidad de disolver, con el tiempo, cualquier mácula en su génesis, corrigiéndose a sí mismo mediante la apertura constante a la revisión y a la inclusión democrática de las minorías. Con esta "concepción dinámica de la constitución"63 evitará cualquier crítica a la circularidad (regressus ad infinitum) que pueda plantear el nacionalismo o el secesionismo. En definitiva, solo porque todos los afectados por determinados poderes (políticos, económicos o sociales) siempre pueden participar en la toma de decisiones relevantes, cabe presuponer legitimidad y legitimación a dichas decisiones.

La reconstrucción habermasiana, tantas veces pegada a la facticidad, no aclara cuáles son los límites de la comunidad ni cómo deben determinarse, que es lo que nos ocupa. Le basta con reconocer lo evidente -la contingencia histórica de las fronteras- para, acto seguido, tratar de hacer justicia a esa contingencia exponiendo cómo deberá organizarse con justicia la comunidad política que caiga dentro de esas fronteras; y cómo deben ser acogidos los residentes y los que pretendan naturalizarse.

\subsubsection{Menos fronteras, sí: hacia una deriva cosmopolita de la democracia}

No obstante, si pretendemos encontrar una solución más última a las objeciones planteadas por los secesionistas, quizás convenga tomar democracia simplemente como "autogobierno" en abstracto, sin saber aún quién será el sujeto del autogobierno. Evitaremos así la acusación de tomar al pueblo como algo dado. Veamos adónde nos conduce nuestro nuevo punto de partida.

\footnotetext{
${ }^{61}$ Habermas (1999), p. 119.

62 Habermas (2004), pp. 141-159.

63 Habermas (2004), p. 153.
} 
Entendemos que un cuerpo se autogobierna mejor en cuanto es capaz de domeñar el mayor número de vicisitudes que le sobrevengan. Esto, que podrían firmar los estoicos, bien parece ser la misma lógica del autogobierno del cuerpo político. Transformaríamos del siguiente modo la definición de Habermas: Sólo pueden pretender validez legítima las normas jurídicas que en un proceso discursivo de producción de normas jurídicas, articulado a su vez jurídicamente, puedan encontrar el asentimiento de todos los sujetos afectados por dichas normas (que intrínsecamente compondrían una comunidad política X que comprendería a todos los afectados).

Es fácil ahora concluir que en un mundo cada vez más interdependiente sólo podemos abocar, como anticipaban los estoicos y como advirtió clarividentemente Kant 64 , con una propuesta jurídico-política que plasme una deriva cosmopolita de la democracia. Se entroniza así la premisa de que la participación deriva de la afectación y no, como parecen pretender los nacionalistas, de la pertenencia. ${ }^{65}$

En primer lugar, y desde un punto de vista meramente conceptual, quizás cabría ahora plantearse la "democraticidad" de un caso límite como el de Checoslovaquia. ¿No parece claro que literalmente se está desempoderando democráticamente a los checos de poder influir en las decisiones, que sin duda les afectarán, del nuevo país vecino, Eslovaquia? Y viceversa. Resulta pues que un proyecto secesionista, al dividir a los conciudadanos, les desempodera democráticamente a todos. Por tanto, todo proyecto secesionista, dejando aparte las causas comprendidas por los mecanismos correctores citados al inicio, disminuye la democracia y, en ese sentido, lo llamamos antidemocrático. Parece más bien que hay una carencia democrática en el hecho de que los no estadounidenses no podamos elegir a Obama..., decisión política que sin duda afecta a nuestro día a día.

En segundo lugar, y tirando del mismo hilo argumental, aumenta el contenido antidemocrático en la medida en que la deriva cosmopolita, que va en sentido inverso a la secesión, parte de una interdependencia que precisamente se acentúa hoy con más fuerza que nunca: nos ahoga una absurda carrera competitiva ("race to the bottom"66). Tras el embedded capitalism de "les 30 glorieuses" (1945-1973), que pusieron en marcha el Estado del bienestar y que se caracteriza por unas políticas keynesianas mediante las cuales el capitalismo estaba políticamente dominado dentro del marco del Estado nacional, los mercados comenzaron a globalizarse y a escaparse de la política. Esto impidió a los Estados estimular el crecimiento económico al tiempo que dirigían la redistribución. Aunque estos problemas se apaciguaron con la liberalización del tipo de cambio y la aceptación de la inflación, pronto se pagó con costes sociales demasiado altos. La estanflación resultante fue la mez-

\footnotetext{
64 Kant (2005).

65 Ruiz Soroa (2011), p. 37.

66 Habermas (2000a), pp. 71-74.
} 
cla de inflación y falta de crecimiento económico. De ahí que el siguiente paso para paliar las diferencias sociales, la creciente financiación por el crédito de los presupuestos públicos, nos haya conducido hasta la crisis financiera actual: un endeudamiento masivo - que no ha paliado las desigualdades desde los 80- ha ahogado las economías estatales. Una crisis que, para colmo, se ve agravada por recetas de austeridad que, además de ser impuestas desde fuera, resultan incompatibles con el Estado social.

Incluso Dahl sabrá ver que la relación que mantienen democracia y capitalismo alberga una tensión intrínseca y que, por tanto, en cierto modo son incompatibles. 67 En ese sentido, se ha señalado que la "ciudadanía social afecta al principio de autonomía del sistema capitalista de mercado, y por tanto sus exigencias, paradójicamente, no pueden alcanzarse más que en el marco de una superación del Estado nacional. De ahí que tengamos que hablar, aunque sea como idea regulativa (o sencillamente, como utopía), de la dimensión cosmopolita de la ciudadanía social". 68

Hoy las transacciones financieras se han multiplicado exponencialmente frente al estancamiento de las del capital productivo. De ahí que el brutal endeudamiento de los Estados, así como el paulatino vaciamiento de los sistemas sociales, deben paliarse fiscalizando el capital financiero. La cesión hacia arriba de soberanía (a la UE, y hacia otras organizaciones internacionales como la OMC) no obedece a otro motivo que el de mantener algo de soberanía popular frente a los mercados. Otra cosa es que en esa cesión de soberanía hacia arriba estén saliendo beneficiados todos los ciudadanos por igual o estén ganando unos cuerpos soberanos más que otros (o sea, unos ciudadanos más que otros), mientras que el resto simplemente irían a rebufo por miedo a las incertidumbres, al caos que impida definitivamente no ya el autogobierno, sino siquiera mantener el estado de derecho.

Philip Pettit, desde el republicanismo, define el autogobierno como la extensión de relaciones de no-dominación. Afirma que "aunque el estado republicano representa un medio indispensable de promoción de la libertad como no-dominación, no hay nada sagrado, desde el punto de vista republicano, en el estado mismo o en la soberanía estatal". ${ }^{69}$ La distancia del organismo decisor con el lugar de implementación de la decisión tiene la pega de que puede ignorar los problemas, pero tendrá

${ }^{67}$ Dahl (1990b). "La propiedad y el control de las empresas contribuyen a la creación de grandes diferencias entre los ciudadanos en la riqueza, el ingreso, el estatus, las habilidades, la información, el control sobre la información y la propaganda, el acceso a los líderes políticos... estas diferencias ayudan a generar significativas desigualdades entre los ciudadanos en lo relativo a sus capacidades y oportunidades para participar como iguales políticos en el gobierno del Estado" (p. 57). Esto es un grave problema puesto que "las libertades políticas requieren la utilización de recursos y, en consecuencia, un acceso seguro y protegido a los recursos es una condición necesaria para el ejercicio de la libertad política” (pp. 81 y s.).

68 De Lucas (1994), p. 139.

69 Habermas (1999), p. 201. 
el codiciado beneficio, clave del republicanismo, de que será un árbitro imparcial: permitirá extender la no-dominación, tarea republicana por antonomasia.

Aclaremos que la simple cesión de soberanía hacia arriba no agotará el contenido normativo de la democracia, no acabarán ahí nuestras reivindicaciones de mayor autogobierno, o sea, de más democracia. El quid será saber si ese poder delegado trata a todos los sujetos políticos que caen bajo su férula como iguales o trata mejor a unos que a otros. El problema en este caso lo ve muy bien Pogge, quien no necesita hacer un análisis marxista para convencer a liberales, kantianos o utilitaristas de que el sistema económico mundial beneficia a los poderosos y perjudica, maniatándolos, a los Estados más pobres: "los menos favorecidos no son simplemente pobres que a menudo mueren por falta de alimentos, sino personas a las que se empobrece y se mata de hambre bajo los esquemas institucionales que compartimos con ellas, y que inexorablemente configuran sus vidas". ${ }^{70}$ Esas instituciones son herencias del pasado que perpetúan hoy injusticias de las que debemos hacernos cargo: así sucede con los cinco miembros permanentes con derecho de veto, que dirigen parcialmente la ONU por haber vencido en la II Guerra Mundial.

De las críticas de Pogge (quien no se atreve a sacar todas las consecuencias del problema que señala ${ }^{71}$ ) se deduce que los ciudadanos más pobres no son dueños de sus destinos, que están a merced de los gobiernos más ricos y de las multinacionales que les financian. ¿Cabe por tanto decir que es democrático un país donde un niño se muere de hambre? Pues no, a menos que por democracia tengamos a esos estándares cuantificables del politólogo: algunos derechos básicos, lucha electoral y mayoritarismo. Si de verdad todos hubiéramos tenido (mientras se fraguaba el actual sistema institucional) 72 o tuviéramos hoy un mismo voto (una misma capacidad de intervenir políticamente en tanto afectados por las decisiones que se toman) para afrontar los problemas que nos corresponden, entonces sí sería creíble las consecuencias que Rawls extrae de su experimento del velo de la ignorancia. Y por eso sería difícil concebir a ese niño muriéndose de hambre.

¿De que este escenario nos resulte inconcebible a corto plazo se deducirá que el concepto de democracia que pretendemos hacer bueno debe ser abandonado? No, pues la democracia es un ideal al que hay que hacer justicia, al que hay que tender. ¿Diremos que EEUU o España no son democracias? No, pero sí que son más $o$ menos democráticas. Como es más democrático el ius solis que el ius sanguinis en tanto criterio de nacionalidad. Y del mismo modo que es más democrático un mundo con ONU que uno sin ella. Y como es más democrática una ONU sin 5 paí-

\footnotetext{
70 Pogge (2005), p. 255.

71 Pogge, (2005), p. 253. "Esto no significa que debamos responsabilizarnos de los efectos más remotos de nuestras decisiones económicas".

72 Sobre la dimensión histórica o temporal de la justicia y la responsabilidad heredada para su reparación (justicia anamnética), ver: Mate (2011), pp. 144-154.
} 
ses con derecho de veto que una con ellos. ¿Serían totalitarios (antidemocráticos) las dos fracciones surgidas de la secesión? Posiblemente no, pero la secesión en sí será antidemocrática y se resentirá en cada uno de los dos nuevos demos el empoderamiento democrático de los ciudadanos.

Por supuesto, en ambos puede haber poliarquía, lucha electoral, mayoritarismo y derechos fundamentales de primera y segunda generación. Pero se perderá autogobierno en dos sentidos: en uno, digamos, más conceptual y político, porque se reduce el espacio de mi influencia ciudadana; y en otro, llamémoslo más sustancial y humano, porque de la secesión puede quedar una parte más débil (de lo que era en el seno del demos primigenio) de cara a soportar las embestidas de un sistema económico internacional que no trata a todos los Estados por igual (algo que sufren los ciudadanos). Y también es evidente que una de las partes (cuyos ciudadanos han perdido - esto es irrefutable - capacidad de autogobierno) puede salir económicamente beneficiada (por eso suele plantearse la secesión), ganar competitividad en esa carrera suicida que denominábamos "race to the bottom", refinanciar mejor su deuda, y satisfacer mejor los derechos sociales que hacen de la democracia no un mero sistema formal de gobierno. En este sentido, hay ciudadanos que perderán capacidad de autogobierno pero ganarán en libertad personal; y otros ciudadanos que perderán en ambas esferas.

\section{Conclusión}

Los argumentos secesionistas se amparan en una pura negatividad analítica que soslaya los problemas prácticos. Les bastaría con demostrar, aferrándose a una concepción sesgada de la democracia, que no hay razones democráticas para oponerse a la secesión (la determinación del demos es algo conceptualmente previo a la democracia) y que tampoco hay razones morales para oponerse (su concepto de democracia puede regir por igual en cualquiera de las dos porciones desgajadas del Estado primero).

Frente a ello afirmamos que desde una perspectiva normativa multiplicar fronteras es antidemocrático. Y que salvo incidencia de factores correctores, es más democrático el Estado primigenio que las dos porciones que de él se desgajen. Y a la vez advertimos que no se trata de perpetuar el statu quo, dando oxígeno a un patrón interestatal del derecho internacional que beneficia a los países (y sus ciudadanos) con más poder de negociación; al tiempo que, en realidad, hunde a todos los gobiernos (no por igual, claro) en una "race to the bottom" condicionada por la falta de un derecho internacional justo y estable que permita fiscalizar a los poderes que escapan al control soberano. 
En otras palabras, de cara al interior la democracia exige una inclusividad que nunca se agota (nunca existirá algo así como el fin de la política) y que siempre será deudora de luchas por el reconocimiento que no deberán perder la perspectiva individual y la búsqueda de igualdad. Y esa misma inclusividad que pretende hacer efectivo el autogobierno, debe conducirnos, de cara al exterior, al movimiento opuesto a la fragmentación del demos: hacia su ampliación. Esto resulta tanto más evidente cuanto más avanza la interdependencia entre Estados y la injusticia que sufren unos se relaciona con el mayor bienestar de otros. Lo propiamente democrático debe ser, pues, la tendencia hacia la paulatina eliminación de fronteras, o al menos, hacia su porosidad y la constitución de una soberanía multinivel (de la que organizaciones como la UE serían pasos intermedios). ${ }^{73}$ Será difícil que la idea de Estado mundial - la inexistencia de fronteras- no funcione, al menos, como idea regulativa.

\section{Referencias bibliográficas}

APPIAH, A. (2008): Mi cosmopolitismo + "las culturas sólo importan si les importan a las personas" (entrevista de D. gamper sachse), Argentina, Katz.

ArtetA, A. (2011): ¿Libertad de elección lingüística?, Claves de razón práctica, $215,30-41$

BENHABIB, S. (2006): Las reivindicaciones de la cultura: Igualdad y diversidad en la era global, Buenos Aires, Katz.

Benhabib, S., Waldron, J., Honig, B., Kymlicka, W., \& Post, R. (2006): Another cosmopolitanism, Oxford; New York, Oxford University Press.

Brunkhorst (2008). State and Constitution. A reply to Scheuerman, Constellations, Vol. 15, No 4, 493-501

Buchanan, A. (2003) Autodeterminación, secesión y primacía del derecho, en McKim, R., \& McMahan, J. (2003): La moral del nacionalismo, Barcelona, Gedisa.

Buchanan, A. (2013): Secesión, Madrid, Ariel.

DAHL, R. A. (1999a): La democracia y sus críticos, Barcelona, Paidós.

DAHL, R. A. (1999b): La democracia, una guía para los ciudadanos, Madrid, Taurus.

DAHL, R. A. (1990a): La poliarquía: Participación y oposición, Madrid, Tecnos.

DAHL, R. A. (1990b): Prefacio a la democracia, Buenos Aires, Grupo Editor Latinoamericano.

\footnotetext{
73 "La crisis de la Unión Europea a la luz de una constitucionalización del derecho internacional. Un ensayo sobre la constitución de Europa": Habermas (2012).
} 
De LucAs, J. (1994): El desafio de las fronteras: Derechos humanos y xenofobia frente a una sociedad plural, Madrid, Temas de Hoy.

Gellner, E. (1988): Naciones y nacionalismo, Madrid, Alianza

Habermas, J. (1988): Ensayos políticos, Barcelona, Península.

HABERMAS, J. (1989): Identidades nacionales y postnacionales, Madrid, Tecnos.

HABERMAS, J. (1999a): Inclusión: ¿incorporación o integración?, La inclusión del otro: Estudios de teoría política, Barcelona etc, Paidós.

HABERMAS, J. (1999b): La lucha por el reconocimiento en el Estado democrático de derecho, La inclusión del otro: Estudios de teoría política, Barcelona etc, Paidós.

HABERmas, J. (2000a): La constelación posnacional, Barcelona, Paidós.

HABERmas, J. (2000b): Aclaraciones a la ética del discurso, Aclaraciones a la ética del discurso, Madrid, Trotta

HABERMAS, J. (2004): El Estado de derecho democrático: ¿una unión paradójica de principios contradictorios?, Tiempo de transiciones, Madrid, Trotta.

Habermas, J. (2005): Facticidad y validez, Madrid, Trotta.

HABERMAS, J. (2009): ¿Tiene aún la democracia una dimensión epistémica? Investigación empírica y teoría normativa, ;Ay, Europa!, Madrid, Trotta.

HABermas, J. (2012): La constitución de Europa, Madrid, Trotta.

Hetcher, M. (1992): The dynamics of secession, Acta Sociologica, vol. 35, No. 4, pp. 267-283

HobsBawm, E. (2000): Naciones y nacionalismo desde 1780, Barcelona, Crítica

Honneth, A. (1997): La lucha por el reconocimiento: Por una gramática moral de los conflictos sociales, Barcelona, Crítica.

KANT, I. (2005): Sobre la paz perpetua, Madrid, Tecnos.

Kymlicka, W. (2003): La política vernácula: Nacionalismo, multiculturalismo y ciudadania, Barcelona, Paidós Ibérica.

Kymlicka, W. (2006): Fronteras territoriales: Una perspectiva liberal igualitarista, Barcelona, Trotta.

Maestre, A. (2011): Modernidad, historia y política, Madrid, Tecnos.

Margalit, A., \& Raz, J. (1990): National self-determination, The Journal of Philosophy, 87, 439-461.

Mate, R. (2011): Tratado de la injusticia, Rubí, Anthropos.

Miller, D. (1995): On nationality, Oxford, Clarendon Press.

Miller, D. (1997): Sobre la nacionalidad: Autodeterminación y pluralismo cultural, Barcelona etc, Paidós.

Ovejero LucAs, F. (2006): Contra cromagnon: Nacionalismo, ciudadanía, democracia, Barcelona, Montesinos.

PÉrez SARrión, G. (2012): La península comercial, Madrid, Marcial Pons.

Pettit, P. (1999): Republicanismo: Una teoría sobre la libertad y el gobierno, Barcelona, Paidós. 
Pogge, T. (2005): La pobreza en el mundo y los derechos humanos, Barcelona etc, Paidós.

Rancière, J. (1996): El desacuerdo: Política y filosofia, Buenos Aires, Nueva Visión.

Ruiz Soroa, J. M. (2011); Nacionalismo y democracia, Claves De Razón Práctica, $218,32-43$.

SÁnchez-Cuenca Rodríguez, I. (2010): Más democracia, menos liberalismo, Madrid, Katz.

Schmitт, C. (1991): El concepto de lo político, Madrid, Alianza

Stiglitz, J. E. (2006): Cómo hacer que funcione la globalización (A. Diéguez, P. Gómez Crespo Trans.). Madrid, Taurus.

Mikel Arteta

mikelarteta@hotmail.com 